\title{
Assessment of gait in toddlers with normal motor development and in hemiplegic children with mild motor impairment: a validity study
}

\author{
Priscilla R. P. Figueiredo ${ }^{1}$, Paula L. P. Silva ${ }^{1,2}$, Bruna S. Avelar ${ }^{1}$, \\ Paula S. C. Chagas ${ }^{3}$, Luísa C. P. Oliveira ${ }^{4}$, Marisa C. Mancini ${ }^{1,5}$
}

\begin{abstract}
Background: The optimization of gait performance is an important goal in the rehabilitation of children with cerebral palsy (CP) who present a prognosis associated with locomotion. Gait analysis using videos captured by digital cameras requires validation. Objective: To evaluate the validity of a method that involves the analysis of videos captured using a digital camera for quantifying the temporal parameters of gait in toddlers with normal motor development and children with CP. Method: Eleven toddlers with normal motor development and eight children with spastic hemiplegia who were able to walk without assistive devices were asked to walk through a space contained in the visual field of two instruments: a digital camera and a three-dimensional motion analysis system, Qualisys Pro-Reflex. The duration of the stance and swing phases of gait and of the entire gait cycle were calculated by analyzing videos captured by a digital camera and compared to those obtained by Qualisys Pro-Reflex, which is considered a highly accurate system. Results: The Intraclass Correlation Coefficient (ICC) demonstrated excellent agreement (ICC >0.90) between the two procedures for all measurements, except for the swing phase of the normal toddlers (ICC $=0.35$ ). The standard error of measurement was less than 0.02 seconds for all measures. Conclusions: The results reveal similarities between the two instruments, suggesting that digital cameras can be valid instruments for quantifying two temporal parameters of gait. This congruence is of clinical and scientific relevance and validates the use of digital cameras as a resource for helping the assessment and documentation of the therapeutic effects of interventions targeted at the gait of children with CP.
\end{abstract}

Keywords: gait; toddlers; cerebral palsy; image processing; computer-assisted; rehabilitation.

\section{HOW TO CITE THIS ARTICLE}

Figueiredo PRP, Silva PLP, Avelar BS, Chagas PSC, Oliveira LCP, Mancini MC. Assessment of gait in toddlers with normal motor development and in hemiplegic children with mild motor impairment: a validity study. Braz J Phys Ther. 2013 July-Aug; 17(4):359-366. http://dx.doi.org/10.1590/S1413-35552012005000105

\section{Introduction}

Gait is a key indicator of the functional capacity and independence of individuals $\mathrm{s}^{1-3}$. Consequently, the acquisition and improvement of this locomotor ability of patients have been a central objective in the rehabilitation process $^{2}$. The implementation of interventions with such focus requires reliable and valid evaluation methods to enable the use of gait analysis to help establish a precise functional diagnosis, with the subsequent definition of therapeutic goals, and to document the effects of interventions ${ }^{1,2,4}$.

Rehabilitation professionals often evaluate locomotor skills of children with motor disabilities and gait prognosis, including of spastic hemiplegic children with mild motor impairment. The mobility

of these children is often observationally evaluated using standardized scales, including the Physicians Rating Scale (PRS) ${ }^{5-7}$ and the Gross Motor Function Measure (GMFM) $)^{6,8-11}$, or by documentation of biomechanical variables, including spatiotemporal gait parameters ${ }^{10,12,13}$. Regardless of the method, the digital camera serves a tool in this process, enabling the performance of patients to be recorded for subsequent analysis.

In the context of scientific research, the evaluation of locomotion is typically based on the kinematic (i.e., the angular displacements of joints and spatiotemporal variables) ${ }^{14-17}$ and kinetic (i.e., the joint moments, joint powers, and ground reaction force) parameters ${ }^{17,18}$ that

\footnotetext{
${ }^{1}$ Graduate Program in Rehabilitation Sciences, School of Physical Education, Physical Therapy and Occupational Therapy (EEFFTO), Universidade Federal de Minas Gerais (UFMG), Belo Horizonte, MG, Brazil

${ }^{2}$ Department of Physical Therapy, EEFFTO, UFMG, Belo Horizonte, MG, Brazil

${ }^{3}$ Department of Elderly, Adult and Maternal and Child Physical Therapy, School of Physical Therapy, Universidade Federal de Juiz de Fora (UFJF), Juiz de Fora, MG, Brazil

${ }^{4}$ Physical Therapist, Belo Horizonte, MG, Brazil

${ }^{5}$ Department of Occupational Therapy, EEFFTO, UFMG, Belo Horizonte, MG, Brazil

Received: 09/24/2012 Revised: 01/28/2013 Accepted: 02/01/2013.
} 
characterize the motor strategies used. Such analysis is performed using computerized systems for motion analysis and force platforms. In the clinical context, gait evaluation rarely uses kinetic parameters because motion analysis systems coupled to force platforms are not available in outpatient clinics, either public or private, with the exception of primary research centers. However, the determination of kinematic measures, particularly temporal parameters, has been increasingly possible in therapeutic settings through the analysis of videos recorded using digital cameras. Examples of those parameters are the duration of both the stance and swing phases of gait and of the entire gait cycle.

Temporal parameters are relevant indicators of gait performance ${ }^{19}$. For example, the onset of and proficiency in gait development are marked by changes in biomechanical variables, including the temporal gait parameters ${ }^{20,21}$. Toddlers exhibit unstable and short steps, a broad stance base, larger amplitudes of hip and knee flexion in the swing phase, and reduced gait speed at the onset of independent walking $^{21,22}$. As gait pattern matures, swing phase speed and time increases while double stance time decreases ${ }^{11,21,22}$. Additionally, the use of temporal parameters enables the differentiation between gait patterns considered normal and those considered pathological, such as the gait patterns of children with cerebral palsy $(\mathrm{CP})^{2,23}$. The gait performance of children with spastic hemiplegia-type $\mathrm{CP}$, compared to that of normal children, is characterized by lower speed and lower single stance time in the most compromised limb, as well as reduced step length and limb asymmetry ${ }^{2,24,25}$. Such changes are most likely due to muscle weakness and impaired dexterity in the affected side of the body, which may hinder weight transfer to and weight bearing capacity of the affected limb during gait ${ }^{2}$. Lower-limb strengthening and dexterity training, combined with the practice of functional ambulation are typical interventions prescribed for those children with the goal of eliciting changes in temporal gait parameters (for example, increasing the duration of the stance phase in the paralyzed limb to improve limb symmetry). Changes in temporal parameters are key indicators of the level of motor impairment in children with $\mathrm{CP}^{8,26}$. Therefore, the relation of those parameters with the level of gait performance appears to be well established in the literature, and moreover, they are parameters that can be clinically documented.

Identification of at least two reference events in the gait cycle, namely initial contact and toeoff, is required to determine the phase-stratified temporal gait parameters. These events delimit the stance and swing phases of a gait cycle ${ }^{27-29}$. The use of force platforms s $^{27,28,30,31}$ and computerized systems for motion analysis has been considered highly accurate methods of defining gait events and describing gait temporal parameters ${ }^{1}$. However, these methods involve complex procedures that are usually restricted to the laboratory setting ${ }^{1}$. Both equipments types have high costs and limitations with respect to clinical applications. Therefore, alternative lowcost, valid methods for assessing gait parameters to guide clinical practices would be relevant for motor rehabilitation $^{30}$.

The visual inspection of videos recorded using digital cameras is an alternative for assessing gait events $^{27}$. Such equipment is affordable and requires no specific location or special setup conditions ${ }^{1}$. However, studies have reported the limitations of using digital cameras for gait analysis, including the long time period spent on analysis, human error and the imprecise nature of visual inspection, given the imperfect video capture procedures ${ }^{17,29}$. Some studies show a significant increase in data consistency when the video analysis uses resources enabling frameby-frame movement visualization in slow motion ${ }^{1,3}$.

Videos recorded using digital cameras are used both clinically and in research studies designed to validate scales for functional analysis of gait ${ }^{5,32,33}$. In those studies, videos captured with digital cameras were used for scoring gait observational scales, and subsequently, the obtained scores were compared to results obtained using more sophisticated methods of three-dimensional gait analysis, including the Qualisys Pro-Reflex ${ }^{\circledR}$. However, the method of gait analysis by digital camera video recording lacks evidence supporting its validity in specific groups of individuals, despite its wide use.

The validity of measures of gait parameters must be known to enable the integration of those parameters into evaluation procedures. Differences in these parameters found before and after treatment may result from the therapeutic effects, measurement errors or both. Knowledge of the magnitude of the error rate of measurements may minimize the risk of over- or underestimating the results of an intervention. That is, such knowledge allows a clinician to determine whether the treatment effects outweigh the measurement errors ${ }^{34}$.

The aim of this study was to evaluate the validity of a clinical method for quantifying the duration of stance and swing phases of gait as well as the duration of the entire gait cycle of toddlers with normal motor development and of children with spastic hemiplegia. The clinical method involved the quantification of the abovementioned temporal 
measurements by analyzing digital camera video recordings. The same measurements were quantified using videos concomitantly recorded by a threedimensional motion analysis system (Qualisys Pro-Reflex, here after referred to as the laboratory method); these videos were used as the reference for the validity analysis of the clinical method. The aim of validating the proposed clinical method for populations with distinct gait patterns (toddlers in the maturation phase and hemiplegic children with a mature gait pattern, albeit adapted to the pathological condition) resulted from both being susceptible to significant changes. The former may change as a result of the natural process of development and the latter due to therapeutic interventions. As a result, the gait of toddlers and hemiplegic children has been evaluated using a digital camera in the clinical and scientific contexts, which emphasizes the significance of validating this method.

\section{- Method}

\section{Sample}

Eleven toddlers with normal motor development in the gait acquisition period (group 1) and eight children with spastic hemiplegia (group 2) participated in this study. The toddlers and hemiplegic children were selected based on convenience. The toddlers' parents were informed of the study at the time of their child's appointment with the pediatrician (a collaborator of the present study). The parents who expressed interest in participating in the study were contacted by the researchers in charge and informed of its objectives and procedures. Children with $\mathrm{CP}$ were recruited from rehabilitation services affiliated with the Universidade Federal de Minas Gerais (UFMG), Belo Horizonte, state of Minas Gerais (MG), Brazil; from the waiting lists of theses services; and from the local community. The children's parents or guardians were informed of the objectives and procedures of the study. In both cases, the parents or guardians who agreed to the participation of their children in the study signed an informed consent form.

The inclusion criteria for group 1 were term birth, no complications in the pre-, peri- and postnatal periods and normal gross motor development according to the Alberta Infant Motor Scale (AIMS) test $^{35}$. The inclusion criteria for group 2 were medical diagnosis of spastic hemiplegic cerebral palsy, age from six to 12 years, ability to understand simple commands and walk without aid (classified at levels I and II of the Gross Motor Function Classification
System - GMFCS) ${ }^{36}$, suggesting mild motor impairment. Additionally, the children with $\mathrm{CP}$ could not have received botulinum toxin injections, received serial casting treatment or undergone orthopedic surgery up to six months before the day of data collection.

The procedures used for data collection in the present study were approved by the Research Ethics Committee of UFMG, under the opinions ETIC No. 609/07 and ETIC No. 585/08.

\section{Procedures and instrumentation}

Data collection was held at the Motion Analysis Laboratory (Laboratório de Análise de Movimento LAM) of the School of Physical Education, Physical Therapy and Occupational Therapy (Escola de EducaçãoFísica, Fisioterapia e Terapia Ocupacional - EEFFTO), UFMG. The children participants were accompanied by their parents or guardians. Initially, passive reflexive markers were attached to the heads of the first and fifth metatarsals and to the calcaneus to enable movement tracking of the forefoot and hindfoot, as required for delimiting the gait events. The markers were placed on the right lower limb for the toddlers and on the affected lower limb for the hemiplegic children.

After marker placement, the children were asked to walk barefoot, without support and/or orthoses, at a normal speed, for a distance of five meters. The location defined for walking was within the visual field of six cameras of Qualisys ProReflex MCU (QUALISYS MEDICAL AB ${ }^{\circledR}, 41112$ Gothenburg, Sweden) motion analysis system and of the digital camera (Sony DCR/DVD 405 Recorder). The digital camera was placed on a tripod, at a perpendicular distance of two meters from the walking area, to record gait performance of the subjects in the sagittal plane. Each child walked ten to 20 times through the established area, depending on his or her willingness, to ensure that a minimum of three cycles suitable for analysis was obtained. The footage should show all of the markers on the foot of the child to be suitable for analysis.

A circuit of infrared light (light-emitting diode, LED), using a small bulb, was designed and placed within the visual field of the digital camera and the Qualisys ProReflex ${ }^{\circledR}$ cameras. This procedure enabled both systems to be synchronized. The Qualisys ${ }^{\circledR}$ cameras enabled delimitation of 120 frames per second $(120 \mathrm{~Hz})$, while the digital camera used in the study enabled the delimitation of 30 frames per second $(30 \mathrm{~Hz})$. The Qualisys ${ }^{\circledR}$ is a highly accurate 
and reliable system that enables the accurate measurement of rapid movements ${ }^{37}$.

After data collection, two researchers, whose interrater reliability is shown in Table 1, independently analyzed the videos, recorded using either a digital camera or the Qualisys $s^{\circledast}$ system. To guarantee that the same cycles would be analyzed with both clinical and laboratory systems their recording was synchronized using a LED circuit.

For the same gait cycle, the times (in seconds) in which the events of initial contact 1, toe-off and initial contact 2 occurred in both systems were manually recorded. For both groups, initial contact 1 was defined as the first time-point at which any part of the foot touched the ground; toe-off was defined as the time-point before which the last part of the foot still in contact with the ground was raised from the ground; and initial contact 2 was defined as the time of new contact of any part of the foot with the ground.

\section{Data reduction}

The outcome variables of the present study were the duration of both stance and swing phases of gait, and the entire gait cycle. The stance phase was calculated by subtracting the time of toe-off from the time of initial contact 1 . The swing phase, in turn, was calculated by subtracting the time of initial contact 2 from the time of toe-off. Finally, the entire gait cycle was calculated by subtracting the time of initial contact 2 from the time of initial contact 1 .

On average, six gait cycles (a minimum of three and a maximum of nine) were analyzed for each of the 19 children, for a total of 123 cycles. That number corresponds to all cycles available for analysis. We excluded the videos in which children deviated from the sagittal plane and/or in which synchrony between the digital camera and the motion capturing system was not achieved due to failure in the LED circuit. The values of duration of the stance and swing phases of gait, and of the entire gait cycle were computed for each selected cycle. Subsequently, the mean of each variable was calculated for each child. This procedure was performed both for the video clips using the digital camera (the clinical method) and the Qualisys system (the laboratory method).

\section{Statistical analysis}

The agreement between the values found for the temporal gait variables using the clinical and laboratory methods was calculated using the intraclass correlation coefficient (ICC) for each group. The level of significance was set at $\alpha=0.05$. The standard error of measurement (SEM) was calculated for each outcome variable (i.e., the duration of both the stance and swing phases and the entire gait cycle) obtained for each instrument.

\section{Results}

Group 1 consisted of 11 toddlers with normal motor development in the gait acquisition period, six boys $(54.5 \%)$ and five girls $(45.5 \%)$, with a mean age of $1.03 \pm 0.07$ years. Group 2 consisted of eight children with spastic hemiplegia, five boys $(62.5 \%)$ and three girls (37.5\%), with a mean age of $7.5 \pm 1.30$ years. In group 2 , one child $(12.5 \%)$ had the left side compromised, and seven $(87.5 \%)$ had the right side compromised. Regarding the severity of motor impairment, five children were classified as level I $(62.5 \%)$ and three as level II (37.5\%) on the GMFCS.

The mean and standard deviation values of each outcome variable are shown in Table 2 .

Table 3 outlines the ICC values for the duration of the stance and swing phases of gait, the ICC values for the duration of the entire gait cycle, as well as the SEMs for each variable and instrument. The ICC reference values used in this study were proposed by Bartko ${ }^{38}$, where ICC magnitudes (1) smaller than 0.40 indicate poor to fair agreement; (2) from 0.41 to 0.60 indicate moderate agreement; (3) from 0.61 to 0.80 good agreement; and (4) from 0.81 to 1.00 indicate excellent agreement. Group 1 (toddlers) showed excellent agreement for the durations of the stance phase and the entire gait cycle and poor to fair agreement for the duration of the swing phase. Regarding group 2 (CP), the agreement was excellent

Table 1. Inter-examiner reliability for the duration of the temporal gait parameters in the analysis of videos obtained by a digital camera and by the Qualisys Pro-Reflex system.

\section{Inter-Examiner Reliability (ICC) Digital Camera $\times$ Qualisys}

$\begin{array}{cccccc}\begin{array}{c}\text { Stance Phase } \\ \text { Camera }\end{array} & \text { Stance Phase } & \text { Swing Phase } & \text { Swing Phase } & \text { Gait Cycle } & \text { Gait Cycle } \\ 0.99 * & \text { Qualisys } & \text { Camera } & \text { Qualisys } & \text { Camera } & \text { Qualisys } \\ & 0.99 * & 0.59 * * & 0.88^{*} & 1.00 * & 1.00 *\end{array}$

*Excellent agreement $(\mathrm{ICC}=0.81 \text { a } 1)^{28}$; **Moderate agreement $(\mathrm{ICC}=0.41 \text { a } 0.60)^{28}$. The values of the ICCs were approximated to maintain two decimal places. 
Table 2. The group mean and standard deviation of the duration of temporal gait parameters.

\begin{tabular}{lcccccc}
\hline \multicolumn{7}{c}{ Means and Standard Deviations Camera Digital $\times$ Qualisys } \\
& $\begin{array}{c}\text { Stance Phase } \\
\text { Camera }\end{array}$ & $\begin{array}{c}\text { Stance Phase } \\
\text { Qualisys }\end{array}$ & $\begin{array}{c}\text { Swing Phase } \\
\text { Camera }\end{array}$ & $\begin{array}{c}\text { Swing Phase } \\
\text { Qualisys }\end{array}$ & $\begin{array}{c}\text { Gait Cycle } \\
\text { Camera }\end{array}$ & $\begin{array}{c}\text { Gait Cycle } \\
\text { Qualisys }\end{array}$ \\
Group 1 (Toddlers) & 0.472 & 0.524 & 0.315 & 0.274 & 0.788 & 0.798 \\
& $(0.129)$ & $(0.110)$ & $(0.016)$ & $(0.032)$ & $(0.138)$ & $(0.126)$ \\
Group 2 (CP) & 0.630 & 0.631 & 0.480 & 0.459 & 1.110 & 1.090 \\
& $(0.117)$ & $(0.087)$ & $(0.042)$ & $(0.065)$ & $(0.142)$ & $(0.133)$ \\
\hline
\end{tabular}

The numbers indicate mean and (standard deviation), in seconds. $\mathrm{CP}=$ Cerebral palsy.

Table 3. The Intraclass Correlation Coefficients (ICC) and standard errors of measurement (SEM) for temporal gait parameters obtained by the digital camera and Qualisys Pro-Reflex system.

Stance Phase Duration

Group 1 (Toddlers)

Group 2 (CP)

SEM $^{\dagger}$

$$
0.93 *
$$

$0.93 *$
Swing Phase Duration

$0.35 * *$

$0.91^{*}$
Gait Cycle Duration

0.99*

0.96*

$\begin{array}{cccccc}\begin{array}{c}\text { Digital } \\ \text { Camera }\end{array} & \begin{array}{c}\text { Qualisys } \\ \text { System }\end{array} & \begin{array}{c}\text { Digital } \\ \text { Camera }\end{array} & \begin{array}{c}\text { Qualisys } \\ \text { System }\end{array} & \begin{array}{c}\text { Digital } \\ \text { Camera }\end{array} & \begin{array}{c}\text { Qualisys } \\ \text { System }\end{array} \\ 0.02 & 0.01 & 0.01 & 0.01 & 0.01 & 0.01\end{array}$

*Excellent agreement $(\mathrm{ICC}=0.81 \text { a } 1)^{28}$; **Weak agreement $(\mathrm{ICC}<0.40)^{28} ; \uparrow \mathrm{SEM}$ in seconds. The values of the ICCs were approximated to maintain two decimal places.

for all three variables. The magnitude of most of the ICCs shows excellent agreement between the measurements performed using the digital camera and the Qualisys system, except for the swing phase in the group of toddlers, which exhibited fair agreement.

Regarding the SEMs, values lower than 0.02 seconds were found for all outcome variables for both measuring instruments.

\section{Discussion}

In this study, excellent agreement (ICC $>0.90$ ) was observed between most temporal gait variables obtained using the digital camera and the Qualisys system for both toddlers with normal development and hemiplegic children. The results suggest that the digital camera is a valid instrument for the clinical quantification of at least two temporal gait parameters in children with and without disabilities.

Specifically, in the group of toddlers, the coefficient was found to be weak ( $\mathrm{ICC}=0.35$ ) for the duration of the swing phase. This low correlation between the measurement of the duration of the swing phase assessed by clinical (digital camera) and laboratory (Qualisys system) methods may be explained if we consider the specificities of the gait acquisition period. The duration of the swing phase is an indicator of stability. The lower stability of toddlers during the gait acquisition period is indicated by their irregular and shorter steps, indexed by a shorter and more variable duration of the swing phase of gait ${ }^{2,20}$. The digital camera video technology used in this study, which enables the delimitation of only 30 frames per second, most likely hindered the identification of gait event times required for calculating the relatively shorter and more variable swing phase of toddlers. This phenomenon did not occur with the data from the Qualisys system, which yields 120 frames per second. Analyses using a digital video camera may be problematic in defining events of short duration because the temporal accuracy of this method is lower. The same rationale can be attributed to the lower inter-rater reliability achieved for the duration of the swing phase in the digital camera footage (ICC $=0.59$ ).

Other authors have used the same instruments as those used in this study, albeit for different purposes. Araújo et al. ${ }^{1}$ developed an observational scale to assess the kinematic parameters representative of gait changes in spastic hemiplegic and diplegic children and tested its validity by comparing the results found using video analysis with those found with the Qualisys system. The scale addressed the ankle/foot, knee, hip and pelvic joints. A very good correlation was found for the knee $(r=0.64, p<0.05)$, and a good correlation was observed for the ankle/foot complex $(r=0.59, \mathrm{p}<0.05)$. The other items showed 
a poor to fair correlation or no correlation with the measurements obtained using the Qualisys system.

Similarly, Dickens and Smith ${ }^{7}$ analyzed the validity of a visual gait scale in children with spastic hemiplegia by comparing video analysis with three-dimensional analysis. The results showed a disagreement between both methods of analysis for the four kinematic parameters studied. The agreement for the position of the hip and knee in the swing phase was poor (kappa $=-0.11$ to 0.07 ) but ranged from fair to moderate (kappa $=0.21$ to 0.51 ) in the stance phase.

The agreement of the data analyzed using the digital camera recording and three-dimensional motion analysis systems of the abovementioned studies was not as high as in the present study. The differences in the magnitude of the coefficients may be explained by the different characteristics of the parameters analyzed. Whereas Araújo et al. ${ }^{1}$ and Dickens and Smith ${ }^{7}$ compared visual and threedimensional analyses of the kinematics of individual joints, the present study used temporal gait variables, which were assessed based on the analysis of twodimensional movements. Generally, the values of the kinematic parameters of individual joints do not show good agreement between both methods because these variables are more specific, complex and require more sophisticated calculations. In contrast, the temporal parameters of the present study are more global variables, and simpler to assess, which may explain the good agreement found between the analyses by video recordings using the digital camera and using the Qualisys system.

The SEM values were equal to or less than 0.02 seconds for measures of duration of stance phase, swing phase and entire gait cycle obtained using both clinical and laboratory analyses. The SEM enables us to quantify the extent to which an instrument or test provides accurate measurements: low SEM values indicate a high level of accuracy and vice versa. In particular, the results found suggest that we can expect a maximum error of \pm 0.02 seconds when estimating the duration of the gait cycle and the stance and swing phases in both the clinical and laboratory methods. For example, we found a value of 0.47 seconds for the duration of the stance phase of toddlers using the digital camera. We may state with $95 \%$ confidence that the true average duration of that phase ranges between 0.45 and 0.49 seconds, indicating a relative error of only approximately $5 \%$ of the value found because the SEM of that measurement was 0.02 seconds. The same reasoning applies to the other measures. In summary, the SEM values found in this study suggest that measurements performed either using a digital camera or the Qualisys system are stable and minimally error-prone.

A study limitation should be noted. Although our results support the use of a digital camera for gait evaluation of children in the clinical context, in this study, this instrument was used in a laboratory setting. This allowed the implementation of multiple procedures to ensure its validity, including training the examiners, having always the same examiner place the markers, and standardizing the data collection setting. The agreement values and SEMs may be less satisfactory in the clinical setting, where implementing the aforementioned procedures may not always be feasible. It is possible that obtaining valid measures of temporal parameters of gait with a digital camera depends on adaptation and standardization of the procedures used during gait recording.

The results of this study show that video analysis by a digital camera recording is a valid procedure for assessing the general phases of gait in normally developing toddlers and in hemiplegic children and, therefore, it is suitable for clinical use. The temporal parameters evaluated in this study would be difficult to measure and identify without some type of video recording resource. The digital camera enables frameby-frame and slow motion visualization, allowing the footage to be rewound so that the same event can be watched multiple times. Rehabilitation professionals may responsibly use this method in therapeutic evaluation and follow up, after considering the rate of error in assessing short-duration phases.

\section{Acknowledgments}

We acknowledge the Minas Gerais State Research Foundation (Fundação de Amparo à Pesquisa do Estado de Minas Gerais - FAPEMIG), for the funding (Health Sciences - Minas Gerais Research Program [CDS - Programa Pesquisador Mineiro] - process No. 00259-10), the Brazilian Federal Agency for the Support and Evaluation of Graduate Education (Coordenação de Aperfeiçoamento de Pessoal de Nivel Superior - CAPES) for the doctoral scholarship, and the National Council for Scientific and Technological Development (Conselho Nacional de Desenvolvimento Científico e Tecnológico - CNPq) for the scientific initiation scholarship granted. We extend our appreciation to Luiz Megale, a collaborator, to Tatiana Pessoa da Silva Pinto, who provided the data on the group of children with cerebral palsy, and to the parents, for consenting the voluntary participation of their children in this study. 


\section{References}

1. Araújo PA, Kirkwood RN, Figueiredo EM. Validade e confiabilidade intra e interexaminadores da Escala Observacional da Marcha para crianças com paralisia cerebral espástica. Rev Bras Fisioter. 2009;13(3):267-73. http://dx.doi.org/10.1590/S1413-35552009005000033

2. Dini PD, David AC. Repeatability of spatiotemporal gait parameters: comparison between normal children and children with hemiplegic spastic cerebral palsy. Rev Bras Fisioter. 2009;13(3):215-22. http://dx.doi.org/10.1590/ S1413-35552009005000031

3. Harris GF, Wertsch JJ. Procedures for gait analysis. Arch Phys Med Rehabil. 1994;75(2):216-25. PMid:8311681.

4. Tanaka MS, Luppi A, Morya E, Fávero FM, Fontes SV, Oliveira ASB. Principais instrumentos para a análise da marcha de pacientes com distrofia muscular de Duchenne. Rev Neurocienc. 2007;15(2):153-9.

5. Wren TAL, Rethlefsen SA, Healy BS, Do KP, Dennis SW, Kay RM. Reliability and validity of visual assessments of gait using a modified physician rating scale for crouch and foot contact. J Pediatr Orthop. 2005;25(5):64650. PMid:16199948. http://dx.doi.org/10.1097/01. mph.0000165139.68615.e4

6. Curry VCR, Mancini MC, Melo AP, Fonseca ST, Sampaio RF, Tirado MGA. Efeitos do uso de órtese na mobilidade funcional de crianças com paralisia cerebral. Rev Bras Fisioter. 2006;10(1):67-74. http://dx.doi.org/10.1590/ S1413-35552006000100009

7. Dickens WE, Smith MF. Validation of visual gait assessment scale for children with hemiplegic cerebral palsy. Gait Posture. 2006;23(1):78-82 PMid:16311198. http://dx.doi.org/10.1016/j.gaitpost.2004.12.002

8. Damiano DL, Abel MF. Relation of gait analysis to gross motor function in cerebral palsy. Dev Med Child Neurol. 1996;38(5):389-96. PMid:8698147. http://dx.doi. org/10.1111/j.1469-8749.1996.tb15097.x

9. Provost B, Dieruf K, Burtner PA, Phillips JP, BernitskyBeddingfield A, Sullivan KJ, et al. Endurance and gait in children with cerebral palsy after intensive body weight-supported treadmill training. Pediatr Phys Ther. 2007;19:2-10. PMid:17304092. http://dx.doi. org/10.1097/01.pep.0000249418.25913.a3

10. Oeffinger D, Gorton G, Bagley A, Nicholson D, Barnes D, Calmes J, et al. Outcome assessments in children with cerebral palsy, Part I: descriptive characteristics of GMFCS Levels I to III. Dev Med Child Neurol. 2007;49:172-180. PMid:17355472. http://dx.doi. org/10.1111/j.1469-8749.2007.00172.x

11. Delalić A, Kapidžić-Duraković S, Tahirović H. Assessment of motor function score according to the GMFM- 88 in children with cerebral palsy after postoperative rehabilitation. Acta Med Acad. 2010;39:21-29.

12. Galli M, Cimolin V, Rigoldi C, Tenore N, Albertini G. Gait patterns in hemiplegic children with Cerebral Palsy:Comparison of right and left hemiplegia. Res Dev Disabil. 2010;31(6):1340-5. PMid:20674265. http:// dx.doi.org/10.1016/j.ridd.2010.07.007

13. Zipp GP, Winning S. Effects of Constraint-Induced Movement Therapy on Gait, Balance and, Functional
Locomotor Mobility. Pediatr Phys Ther. 2012; 24(1):648. PMid:22207472. http://dx.doi.org/10.1097/ PEP.0b013e31823e0245

14. Öberg T, Karsznia A, Öberg K. Basic gait parameters: reference data for normal subjects, 10-79 years of age. J Rehabil Res Dev. 1993;30(2):210-23. PMid:8035350.

15. Wall JC, Scarbrough J. Use of a multimemory stopwatch to measure the temporal gait parameters. J Orthop Sports Phys Ther. 1997;25(4):277-81. PMid:9083947.

16. Sutherland DH, Olshen R, Cooper L, Woo SL. The development of mature gait. J Bone Joint Surg. 1980;62:336-53. PMid:7364807.

17. Chung TM. Avaliação cinética e cinemática da marcha de adultos do sexo masculino. Acta Fisiátrica. 2000;7(2):61-7.

18. Russell S, Bennett B, Sheth P, Abel M. The gait of children with and without cerebral palsy: work, energy, and angular momentum. J Appl Biomech. 2011;27:99107. PMid:21576717.

19. Lianza S, Gomes C, Consenso Nacional sobre Espasticidade. Diretrizes para diagnósticos e tratamentos. São Paulo: Sociedade Brasileira de Medicina Física e Reabilitação; 2001.

20. Adolph KE. Motor/physical development: locomotion. In: Haith MM, Benson JB, editors. Encyclopedia of infant and early childhood development. San Diego: Academic Press; 2008. p. 359-73. http://dx.doi.org/10.1016/ B978-012370877-9.00104-3

21. Adolph K, Vereijken B, Shrout PE. What Changes in Infant Walking and Why. Child Dev. 2003;74(2):475-497. PMid:12705568. http://dx.doi. org/10.1111/1467-8624.7402011

22. Ivanenko YP, Dominicini N, Lacquaniti F. Development of Independent Walking in Toddlers. Exerc Sport Sci Rev. 2007;35(2):67-73. PMid:17417053. http://dx.doi. org/10.1249/JES.0b013e31803eafa8

23. Kirkwood RN, Franco RLLD, Furtado SC, Barela AMF, Deluzio KJ, Mancini MC. Frontal plane motion of the pélvis and hip during gait stance discriminates children with diplegia levels I and II of the GMFCS. ISRN Pediatr. 2012;2012:1-10. PMid:22792478 PMCid:PMC3389695. http://dx.doi. org/10.5402/2012/163039

24. Norlin R, OdenrickP. Development of gait in spastic children with cerebral palsy. J Pediatr Orthop. 1986;6(6):674-80. http://dx.doi.org/10.1097/01241398-198611000-00006

25. Wang X, Wang Y. Gait analysis of children with spastic hemiplegic cerebral palsy. Neural Regen Res. 2012;7(20):1578-1584.

26. O’Malley JM, Abel MF, Damiano LD. Fuzzy clustering of children with cerebral palsy based on temporal-distance gait parameters. IEEE Trans Rehabil Eng. 1997;5(4):3009. PMid:9422455. http://dx.doi.org/10.1109/86.650282

27. Hreljac A, Marshall RN. Algorithms to determine event timing during normal walking using kinematic data. J Biomech. 2000;33(6):783-6. http://dx.doi.org/10.1016/ S0021-9290(00)00014-2

28. O'Connor CM, Thorpe SK, O’Malley MJ, Vaughan CL. Automatic detection of gait events using kinematic data. 
Gait Posture. 2007;25(3):469-74. PMid:16876414. http:// dx.doi.org/10.1016/j.gaitpost.2006.05.016

29. Zeni JA Jr, Richards JG, Higginson JS. Two simple methods for determining gait events during treadmill and overground walking using kinematic data. Gait Posture. 2008;27(4):710-4. PMid:17723303 PMCid:PMC2384115. http://dx.doi.org/10.1016/j. gaitpost.2007.07.007

30. Catalfamo P, Moser D, Ghoussayni S, Ewins D. Detection of gait events using F-Scan in-shoe pressure measurement system. Gait Posture. 2008;28(3):420-26. PMid:18468441. http://dx.doi.org/10.1016/j.gaitpost.2008.01.019

31. Desailly E, Daniel Y, Sardain P, Lacouture P. Foot contact event detection using kinematic data in cerebral palsy children and normal adults gait. Gait Posture. 2009;29(1):76-80. PMid:18676147. http://dx.doi. org/10.1016/j.gaitpost.2008.06.009

32. Brown CR, Hillman SJ, Richardson AM, Herman JL, Robb JE. Reliability and validity of the Visual Gait Assessment Scale for children with hemiplegic cerebral palsy when used by experienced and inexperienced observers. Gait Posture. 2008;27(4):648-52. PMid:17913500. http:// dx.doi.org/10.1016/j.gaitpost.2007.08.008

33. Wren TAL, Do KP, Hara R, Dorey FJ, Kay RM, Otsuka NY. Gillette Gait Index as a gait analysis summary measure: comparison with qualitative visual assessments of overall gait. J Pediatr Orthop. 2007;27(7):765-8. PMid:17878782. http://dx.doi.org/10.1097/BPO.0b013e3181558ade
34. McGinley JL. The reliability of three-dimensional kinematic gait measurements: A systematic review. Gait Posture. 2009;29(3):360-9. PMid:19013070. http://dx.doi. org/10.1016/j.gaitpost.2008.09.003

35. Piper MC, Darrah J. Motor assessment of the developing infant. Philadelphia: W.B.Saunders Company; 1994.

36. Palisano RJ, Rosenbaum P, Bartlett DJ, Livingston MH. Content validity of the expanded and revised Gross Motor Function Classification System. Dev Med Child Neurol. 2008;50(10):744-50. PMid:18834387. http:// dx.doi.org/10.1111/j.1469-8749.2008.03089.x

37. Qualisys Medical AB. Qualisys Track Manager User Manual. Gothenburg; 2004.

38. Bartko JJ. The Intraclass Correlation Coefficient as a measure of reliability. Psychol Rep. 1966;19:3-11. PMid:5942109. http://dx.doi.org/10.2466/pr0.1966.19.1.3

\section{Correspondence}

\section{Marisa C. Mancini}

Escola de Educação Física, Fisioterapia e Terapia Ocupacional Colegiado de Pós-graduação em Ciências da Reabilitação

Av. Antônio Carlos, 6627, Campus Pampulha CEP 31270-901, Belo Horizonte, MG, Brasil e-mail: mcmancini@ufmg.br, marisacmancini@gmail.com 